\title{
The Reaction Behavior of Direct Reduced Iron (DRI) in Steelmaking Slags: Effect of DRI Carbon and Preheating Temperature
}

\author{
Erfan Sharifi and Mansoor Barati
}

\author{
Version Post-print/Accepted Manuscript \\ Citation Sharifi, E. \& Barati, M. Metall and Materi Trans B (2010) 41: 1018. \\ (published version) https://doi.org/10.1007/s11663-010-9401-5
}

Publisher's statement This is a post-peer-review, pre-copyedit version of an article published in Metallurgical and Materials Transactions B. The final authenticated version is available online at: http://dx.doi.org/10.1007/s11663-010$9401-5$

How to cite TSpace items

Always cite the published version, so the author(s) will receive recognition through services that track citation counts, e.g. Scopus. If you need to cite the page number of the author manuscript from TSpace because you cannot access the published version, then cite the TSpace version in addition to the published version using the permanent URI (handle) found on the record page.

This article was made openly accessible by $U$ of $T$ Faculty. Please tell us how this access benefits you. Your story matters. 
Page 1 of 14

\title{
The Reaction Behavior of DRI in Steelmaking Slags: Effect of DRI Carbon and Preheating Temperature
}

\author{
ERFAN SHARIFI and MANSOOR BARATI \\ Department of Materials Science and Engineering, University of Toronto, Toronto, ON, Canada M5S 3E4
}

\begin{abstract}
An experimental study was undertaken to quantify the rate of DRI decarburization in steelmaking slag using the constant-volume pressure increase technique. Experiments were conducted by dropping DRI pellets into molten slag at temperatures from $1500^{\circ} \mathrm{C}$ to $1600^{\circ} \mathrm{C}$. Further experiments were carried out in which the DRI pellets were preheated while the slag temperature remained constant. The effect of initial carbon content and preheating temperature of the DRI on the reaction rate was investigated. The decarburization of DRI appears to comprise of two stages; reaction with the FeO of DRI, followed by further decarburization through the iron oxide of slag. Carbon has a significant effect on the kinetics of both stages while the preheating temperature mainly influences the rate of decarburization between FeO and carbon inside the pellet.
\end{abstract}

\section{INTRODUCTION}

In an earlier study, Li and Barati (6) have described the behavior of DRI in slags with various FeO contents and basicities. $\mathrm{X}$-ray fluoroscopy observations provided a qualitative insight into the mechanism of melting and decarburization of DRI. This work is an extension of the previous investigation, aiming to examine the effect of DRI carbon content, slag temperature, and DRI pellet preheating temperature on the kinetics of decarburization of the DRI.

The behavior of DRI in steelmaking slags has been the subject of several other studies. Sadrnezhad and Elliott (7) conducted an experimental study on the melting rate of DRI pellets in $\mathrm{CaO}-\mathrm{FeO}-\mathrm{SiO}_{2}$ slags. The experiments involved immersing DRI pellets inside the slag to measure the rate of gas evolution. The measurements were carried out by observing the number of gas bubble sites on the surface of molten slag. They found two peaks at $750{ }^{\circ} \mathrm{C}$ and $1000{ }^{\circ} \mathrm{C}$ in the gas evolution versus temperature curves and justified that the peaks corresponded to the reduction of magnetite to wustite (Reaction [1]) and wustite to iron (Reaction [2]), respectively. This conclusion was based on the assumption that the DRI pellet contained considerable quantity of magnetite. However, due to the fact that commercial DRI pellets contain little magnetite, other researchers $(6,8,9)$ considered Eq. [2] as the dominant reaction in DRI-slag interactions.

$\mathrm{Fe}_{3} \mathrm{O}_{4}+\mathrm{C}=3 \mathrm{FeO}+\mathrm{CO}_{(\mathrm{g})}$

$\mathrm{FeO}+\mathrm{C}=\mathrm{Fe}+\mathrm{CO}_{(\mathrm{g})}$

The carbon shown in the above reactions can be as free, dissolved, or $\mathrm{Fe}_{3} \mathrm{C}$. It has been reported (10,11) that over 70\% of the carbon in the DRI is in the form of iron carbide. However, it is likely that this metastable compound may decompose at the high DRI-slag reaction temperatures, resulting in carbon being dissolved in iron. 
Page 2 of 14

Sadrnezhad and Elliott also discussed that neither pellet size nor heating rate of DRI pellets affect the volume of gas evolved from the reaction; instead, the gas evolution depends directly on the chemical composition of pellet and slag. In another study, Goldstein et al. (8) released DRI pellets into the typical steelmaking slag $\left(40 \mathrm{CaO}-41 \mathrm{SiO}_{2},-9 \mathrm{FeO}-10 \mathrm{Al}_{2} \mathrm{O}_{3}\right.$ wt pct). The reaction was visualized using x-ray fluoroscopy. The reaction started by an initial incubation period of 8-10 s followed by a 20-30 s rapid gas evolution. They concluded that the behavior of DRI in slag is similar to that of Fe-C drops. On the other hand, for Fe-C/slag reactions, Mulholland et al. (12) observed a gas layer around the Fe-C drops. They found that the gas halo disappears when the slag foaming ends. Furthermore, it was noted that the size of gas halo depends on the rate of reaction: higher rate of gas evolutions results in the formation of a larger gas halo around the pellet. A similar behavior was observed by Gare and Hazeldean (13). In another study by Min and Fruehan (14), a mechanism was proposed for the reaction between $\mathrm{Fe}-\mathrm{C}$ drops and $\mathrm{FeO}$ in the slag based on the observation of gas halo, in which the gaseous $\mathrm{CO}$ reduces the slag $\mathrm{FeO}$ and produces $\mathrm{CO}_{2}$ as demonstrated by Reaction [3]. The $\mathrm{CO}$ is then regenerated thorough the Boudouard reaction (Reaction [4]), consuming carbon of the Fe-C drop.

$\mathrm{CO}_{(\mathrm{g})}+\mathrm{FeO}=\mathrm{Fe}+\mathrm{CO}_{2(\mathrm{~g})}$

$\mathrm{CO}_{2}+\mathrm{C}=2 \mathrm{CO}_{(\mathrm{g})}$

Goldstein et al. (8) suggested a similar mechanism, i.e. the reaction proceeding through an intermediate gas layer, in the DRI-slag reaction. This was confirmed in the recent study by Li and Barati (6) where direct observations showed a gas film around the DRI for a large fraction of the reaction duration. They investigated the behavior of DRI pellets in the slag and postulated three scenarios for the decarburization, each different in terms of the DRI movement inside the slag and the gas halo formation around the pellet; depending on the slag FeO content and viscosity. Generally, DRI pellet was converted to a metal drop that sunk to the bottom of crucible, after an active reaction period of 16 to $26 \mathrm{~s}$. They also found a two stage behavior in the gas evolution measurements. The first stage corresponds to the carbon and $\mathrm{FeO}$ reaction within the pellet, while the second stage corresponds to the reaction between the remaining carbon and the $\mathrm{FeO}$ inside the slag.

Although a general knowledge of interactions between DRI and slag has been achieved through the previous investigations, the role of several critical variables on the reaction kinetics and mechanism have not been understood. For example, based on the findings in Fe-C/slag interactions $(12,13,14)$ it is anticipated that carbon content of DRI may have a significant impact on its behavior in slags. However, the effect of carbon on DRI-slag reaction has not been studied previously. Moreover, recent introduction of Hot Charging technology $(2,15,16)$ that allows direct discharge of DRI at high temperature to EAF demands a study on the effect of DRI preheating temperature on its reactions with slag. Therefore, in an attempt to achieve a comprehensive understanding of DRI-slag interactions, the effects of DRI carbon level, slag temperature, and DRI preheating temperature on the kinetics of reaction are investigated in the present study.

\section{Experimental}

\section{Materials}

The slag composition was fixed in the present work (Table 1) since the effects of varying basicity and FeO contents of slag have been reported earlier (6). Basicity defined as the $\mathrm{V}$ ratio $\left(\mathrm{B}=(\mathrm{MgO}+\mathrm{CaO}) /\left(\mathrm{SiO}_{2}+\mathrm{Al}_{2} \mathrm{O}_{3}\right)\right.$ was adjusted to 2.0 while $\mathrm{FeO}$ and $\mathrm{MgO}$ contents were controlled at 22 and $10 \mathrm{wt}$ pct, respectively. The slag was prepared by mixing laboratory grade powders of the above oxides. $\mathrm{FeO}$ was supplied in the form of mill scale.

$<<$ Table 1 >

Table 2 shows the average composition of the commercial DRI pellets (supplied by ArcelorMittal - Quebec, Canada) used in the present study. As seen, the average carbon content of pellets was $2.2 \mathrm{wt}$ pct, while there were considerable variations 
in the carbon of individual pellets used in the experiment, as shown in Figure 1. Such variations were beneficial in order to study the effect of DRI carbon on the reaction rate as explained below.

Controlling carbon content of each pellet was essentially impractical as commercial pellets were to be used. On the other hand, determination of carbon before the experiments involves destructive testing, rendering the pellet useless. In order to cover a range of carbon content for each experimental condition, enough number of pellets $(\sim 8)$ were released into the slag under each condition of slag and pellet preheating temperature. The carbon content was calculated at the end of each experiment through mass balance by taking into account the carbon evolved as gas (Reaction [2]) together with the carbon remained in the metal droplet.

\author{
$<<$ Table 2〉> \\ $<<$ Figure 1 >
}

\title{
2.Experimental Procedure
}

The experiments involved the release of a suspended DRI pellet into the molten slag, as shown in Figure 2, followed by measuring the rate of gas evolution. About 100 grams of slag powders were mixed thoroughly and pressed into several disks that were then placed inside the crucible. The crucible made of high density; high purity (99.9\%) magnesia was $50 \mathrm{~mm}$ in diameter and $152 \mathrm{~mm}$ in height. It was held in the hot zone of the vertical tube furnace using an alumina pedestal. The alumina work tube was sealed completely by two water-cooled stainless steel caps. A B-type (Pt-30\%Rh/Pt-6\%Rh) thermocouple touching the bottom of the crucible was used to monitor the slag temperature. While the pellet and slag were held in position inside the furnace, the temperature was ramped up to the target temperature at the rate of $1.7^{\circ} \mathrm{C} . \mathrm{min}^{-1} \mathrm{using}$ a programmable controller. During this slag-melting stage, the furnace was purged by passing high purity argon (below 5 ppm oxygen) to avoid oxidation of the slag and the pellet. The gas flow was then stopped and the furnace was fully sealed. Gas tightness is checked by monitoring the inside pressure of the work tube using a high accuracy (690 Pa) pressure transducer attached to the gas outlet.

Two sets of experiments were conducted with a major difference being the initial temperature of the pellet; pre-heated and non-preheated. Correspondingly, two experimental designs with a minor difference in the DRI position were utilized. In the non-preheating experiments, the DRI pellet was held at the top of the furnace using a magnet that is located outside the furnace just above the tube. Using this arrangement, the pellet temperature reaches about $70{ }^{\circ} \mathrm{C}$ before it is dropped into the slag by removing the magnet. Once the DRI enters the slag, the pressure rise resulted from the DRI-slag reaction is measured using the pressure transducer. The pressure was recorded at the time intervals of $1 \mathrm{~s}$. In this set of experiments, slag temperature was controlled to 1500,1550 , and $1600^{\circ} \mathrm{C}$.

\section{$<<$ Figure 2>>}

In the second set of experiments, slag temperature was fixed (at $1550^{\circ} \mathrm{C}$ ) while the pellet was preheated to three temperatures: 200,400 , and $600{ }^{\circ} \mathrm{C}$. Preheating was achieved by hanging the DRI pellet inside the furnace at a proper position. This method was preferred over external heating of the pellet to avoid possible oxidation or temperature drop during the transfer to the furnace, also to facilitate maintaining the furnace seal. The DRI pellet was held by a copper wire in the upper part of the furnace in which the temperature is relatively low. The wire was passed through the needle of a syringe. The temperature distribution of this part of furnace and also the time needed for the pellet to reach the certain temperature were calibrated earlier as shown in a temperature versus distance graph in Figure 2. This curve was obtained from the separate calibration tests using a K-type thermocouple inserted into the DRI pellets and held in various positions along the tube. As depicted, the DRI pellet can be preheated up to $\sim 1400^{\circ} \mathrm{C}$ by changing the initial position of pellet. When 
Page 4 of 14

the DRI reached the desired temperature, it was released into the molten slag by cutting the wire. Subsequently, the system was immediately sealed by putting a syringe filled with argon on the needle.

In both sets of experiments, the volume of gas released was calculated from pressure increase, using a correlation obtained through calibration prior to each experiment.

\section{Results and Discussion}

\section{Gas Evolution Behavior}

Figure 3 shows the gas evolution curves corresponding to slag temperatures of 1550 and $1600^{\circ} \mathrm{C}$. As seen, depending on the reaction conditions such as slag temperature and carbon content, a different behavior may be observed. In Figure 2 , for the pellet containing 3.18 wt pet carbon and dropped into slag at $1600{ }^{\circ} \mathrm{C}$, a two stage behavior was identified: a rapid gas evolution period (identified as region 1), followed by a substantial decrease in the rate of gas evolution (region 2). A similar trend was obtained after dropping majority of pellets into the molten slag. This conforms to the behavior previously observed in the other studies $(6,12,13,13,17)$. It is suggested that the first stage corresponds to the reaction between the carbon and $\mathrm{FeO}$ within the pellet. After $\mathrm{FeO}$ of the pellet is consumed completely, the remaining carbon reacts with the FeO of slag (second stage). However, in several experiments, a different behavior with three distinctive stages of gas evolution was noted. As an example of these cases, the gas evolution of a pellet with 2.83 wt pct carbon released into slag at $1550^{\circ} \mathrm{C}$ is shown in Figure 3. In a somewhat similar observation, Gare and Hazeldean (13) found a lull period in the carbon against time curves after the first rapid decarburization. They suggested that at the end of first period as the carbon content drops, the rate of decarburization decreases and consequently, the gas halo around the pellet begins to collapse. Subsequently, the oxygen required to reacts with the remaining carbon is supplied by the iron oxide from the slag bulk. Therefore, the diffusion of oxygen from the slag phase to the metal-slag interface may take a finite time, after which the reaction proceeds, but at a slower rate. Accordingly, a complete picture of the DRI-slag interactions that supports the three-stage feature of these experiments may be explained as following.

$<<$ Figure $3>>$

In the reaction between DRI and slag, decarburization first takes place through the FeO present within the pellet, once proper local temperature is reached (Stage 1). The reaction continues until FeO of pellet is consumed. Provided that DRI contains additional carbon, the reaction will proceed through the consumption of slag FeO (Stage 2). However, the reaction is first slowed or practically stopped (transitional stage) because of four possible reasons; (a) when pellet is still partially solid, decarburization by slag involves diffusion of carbon from within the pellet to the slag-pellet interface (b) melting of pellet that would accelerate the reactions requires a finite time for the heat transfer to pellet, this time is extended because of the decrease in the gas evolution rate that in turn hinders movement of pellet and reduces the rate of heat transfer, (c) decarburization by slag requires mass transfer of $\mathrm{FeO}$ in the slag phase, that is slowed substantially when gas release of the first stage is stopped, and (d) similar to the decarburization of liquid $\mathrm{Fe}-\mathrm{C}$ drops (18), oxygen must diffuse through the liquid metal and super-saturate the drop before $\mathrm{CO}$ bubbles are formed and released. Consequently, it is reasonable that the third step of the reaction takes over after some period of inactivity or slow interactions. It is believed that the same mechanism holds for all pellets. However, the duration of the transitional stage is not long enough to be distinctly seen in all experiments. For example, higher temperatures of slag may contribute to the shortening of this stage by increasing the rates of both heat transfer and mass transport of $\mathrm{FeO}$, as well as accelerating the rates of diffusion of carbon to the pellet surface and oxygen to the liquid metal. 
Page 5 of 14

In some experiments only the first stage of gas release was observed. In other words, the reaction between carbon and $\mathrm{FeO}$ inside the slag does not occur or has a small contribution to the overall decarburization. Subsequent calculation of carbon content of these pellets showed that they contained typically less than $1.8 \mathrm{wt} \mathrm{pc} \mathrm{C}$, indicating that the $\mathrm{FeO}$ content of pellet has been sufficient for complete oxidation of the carbon in these experiments.

\section{Effect of Carbon}

The rate of reaction in each stage is estimated by measuring the average slope of the curve in the corresponding region. The rate of the first stage was denoted by mole of gas per second per volume of pellet while the second stage rate was described by mole of gas per second per unit area of the reaction interface. Figure 4 shows the rate of reaction between DRI and slag in the first stage as a function of carbon content for the three slag temperatures examined. As seen, increasing the carbon content of DRI leads to a slight increase in the rate of reaction. A limited number of studies $(12,13,14)$ had observed this behavior even though their findings were rather qualitative. For example, Mulholland et al. (12) found larger rates of decarburization for $\mathrm{Fe}-\mathrm{C}$ drops containing higher carbon in their visual observations.

Figure 5 presents the rate of DRI decarburization in the second stage as a function of carbon content for pellets released at $70{ }^{\circ} \mathrm{C}$. Similar to the first stage, carbon has an increasing effect on the rate of reaction but the relationship is stronger in this case. Also, increasing the slag temperature appears to increase the rate, particularly at higher carbon levels.

$<<$ Figure 4>>

$<<$ Figure 5>>

Previous researchers $(7,8)$ have discussed that the first stage of reaction between DRI and slag is controlled by heat transfer from slag to pellet. It is thus expected that the chemical composition of DRI including its carbon content does not affect the rate, unless heat transfer is limited by thermal conduction within the pellet and conductivity of the pellet is significantly affected by its carbon content. The results presented in Figure 4 do not support a reaction rate that is controlled by heat transfer. This is based on the fact that the role of carbon in heat transfer could be decreasing thermal conductivity of pellet by forming more iron carbide at the expense of consuming more iron. Therefore, carbon should in fact decrease the rate, if its role was solely on the heat transfer rate.

Role of carbon in increasing the reaction rate may be justified by a process that at least in part is controlled by a chemical reaction. Increasing the carbon content of pellet may result in higher rates, if $\mathrm{FeO}-\mathrm{C}$ reaction, alone or in combination with heat transfer, is the rate determining step. Larger gas evolution rate results in more intense agitation of slag that in turn increases the rate of heat transfer. Therefore the carbon-FeO reaction indirectly, and through an enhanced heat transfer selfaccelerates itself.

In the second stage, as shown earlier (Figure 5), the increasing effect of carbon is more pronounced than the first stage. Li and Barati (6) found that $\mathrm{FeO}$ content of slag strongly affects the rate of decarburization in the second stage. They proposed that the rate of reaction is controlled by the rate of $\mathrm{FeO}$ mass transport from the bulk of slag to the DRI-slag interface. This mechanism can also justify the role of carbon. Since for the pellets with higher carbon the rate is higher at the end of the first stage, it is reasonable to suppose that mass transfer of $\mathrm{FeO}$ is faster under those conditions. Thus, the second reaction takes over under more flux of $\mathrm{FeO}$ to the pellet and proceeds with a higher rate.

The practical implication of the effect of carbon is that DRI with higher carbon can give rise to both faster reactions and larger gas volume, hereby improving the slag foaming. This could in turn contribute to reduced level of electrical and acoustic noises of EAF, higher quality steel with lower dissolved nitrogen and hydrogen, improved thermal efficiency, and longer refractory life.

\section{Effect of Slag Temperature}


Page 6 of 14

Effect of slag temperature on the DRI reaction kinetics has not been studied in details previously. However, it is known that increasing temperature will result in faster reactions (12). In the present research, the slag temperature varied from $1500^{\circ} \mathrm{C}$ to $1600^{\circ} \mathrm{C}$. As seen in Figure 4 and Figure 5, in the both reaction stages, raising the slag temperature accelerates the rate of reaction. Min and Fruehan (14) have reported that for a $50{ }^{\circ} \mathrm{C}$ increase in temperature, the rate of reaction is doubled. Assuming that chemical reaction is the rate limiting step, Murthy et al. (19) showed that the magnitude of the increase depends on the activation energy of the corresponding reaction. Considering an Arrhenius type of relationship between rate constant and the temperature, the rate constant can be written as:

$k=k_{0} \exp (-E / R T)$

where $k_{0}$ is a frequency factor, $\mathrm{E}$ is the activation energy and $\mathrm{R}$ is the universal gas constant. Therefore, assuming a linear relationship between the rate and $\mathrm{FeO}$ content of slag they postulated that:

$\ln r_{0}=\ln (\% \mathrm{FeO})+\ln k_{1}+\ln k_{0}-(E / R T)$

where $r_{0}$ is the rate and $k_{1}$ is the constant relating $\% \mathrm{FeO}$ to its concentration $\mathrm{C}_{\mathrm{FeO}}$.

The correlation holds when the controlling mechanism is reaction control. Otherwise, predicting the effect of temperature is rather difficult due to the large number of physicochemical properties and chemical reaction steps that are affected by temperature.

Form Figure 5, it is also apparent that in the second stage, the slag temperature not only increases the rate of reaction but also, strengthens the dependence of the reaction rate on carbon. As discussed earlier, it was suggested that the second stage is influenced by the mass transfer of FeO inside the slag. Also, Min and Fruehan (14) proposed that the reaction is controlled by a mixed mechanism comprising of $\mathrm{CO}_{2}$ diffusion in the gas halo and $\mathrm{FeO}$ transport through the slag and metal-slag interface. Clearly, increasing the slag temperature gives rise to higher rates through promoting the rate of mass transfer as a result of a more fluid slag.

\section{Effect of Preheating Temperature}

Figures 6 and 7 present the rates of first and second steps of reaction, respectively, as a function of carbon content for various preheating temperatures. From Figure 6, it is apparent that preheating increases the rate of the first step of decarburization. Since the reaction between $\mathrm{FeO}$ and $\mathrm{C}$ is endothermic, heat transfer to the pellet may become the rate limiting step. Clearly, preheating increases the thermal energy of the pellet, giving rise to higher extent of reaction for a given period of time. Also, earlier it was discussed that the rate of this step of the reaction could in part be limited by the chemical reaction of $\mathrm{FeO}$ and $\mathrm{C}$. Higher rate of reaction under the reaction control conditions is justified by the increase in the temperature profile within the pellet. The respective effects of temperature and carbon content on the rate of first stage suggest that a mixed mechanism is more likely controlling the overall rate of the first stage. While heat must be supplied to satisfy the endothermic nature of the reaction, local concentrations of $\mathrm{C}$ and $\mathrm{FeO}$ could also be limiting to the reaction. Figure 6 support this mixed control mechanism by showing larger slope in the rate-C correlations for higher preheating temperatures. Increasing the initial temperature of pellet reduces the thermal energy requirement to an extent that heat transfer plays a smaller role; thus, carbon becomes a more effective factor.

$$
\begin{aligned}
& <<\text { Figure } 6>> \\
& <<\text { Figure } 7>>
\end{aligned}
$$

Figure 7 indicates that preheating has no considerable effect on the decarburization rate, as unlike the first stage, the rate of reaction is only a function of the DRI carbon content. This behavior was expected based on the suggested mechanism for 
Page 7 of 14

this step. Essentially, when the second stage takes over, after typically $30 \mathrm{~s}$, the pellet has reached a temperature well above the preheating temperatures. Thus the preheating has little effect on the rate of second stage, although faster rate of the first stage can give rise to faster $\mathrm{FeO}$ mass transport in the earlier periods of the slag- $\mathrm{C}$ reaction. This latter effect was however not noticeable.

The effect of preheating on the overall decarburization rate may be seen in the total time of gas evolution. Previous studies $(6,14)$ have shown that the time of DRI-slag reaction is a function of $\mathrm{FeO}$ content of slag. Li and Barati (6) found a decrease in the reaction times as a result of an increase in the $\mathrm{FeO}$ content of slag in their experiments. Min and Fruehan (14) suggested that the reaction time is highly dependent on the slag chemistry. In the present study, the overall time of reaction was measured for each pellet. As seen in Table 3, the average reaction times for the pellets for four preheating temperatures are shown. It is clear that the variations in the reaction times are relatively large $( \pm 18 \mathrm{~s})$ due to the different carbon content and size of these pellets. However, it is evident that as the preheating temperature increases from $70{ }^{\circ} \mathrm{C}$ to $600{ }^{\circ} \mathrm{C}$, the average reaction time is reduced from $62.0 \mathrm{~s}$ to $47.3 \mathrm{~s}$. This is expected as preheating the DRI pellets decreases the time needed to initiate the reaction between the carbon and $\mathrm{FeO}$ thereby reduces the overall reaction time. This introduces a potential to increase the productivity of DRI-based steelmaking by preheating the DRI. This is an additional advantage to the energy savings associated with charging hot DRI to steelmaking electric furnaces.

\section{Conclusions}

An experimental study of DRI reaction with a steelmaking slag ( $\mathrm{FeO}-\mathrm{CaO}-\mathrm{MgO}-\mathrm{Al}_{2} \mathrm{O}_{3}-\mathrm{SiO}_{2}$ ) was undertaken. Effects of several variables including carbon content of DRI, slag temperature and preheating temperature of DRI on the reaction kinetics were studied. The major findings include:

1.The decarburization of DRI pellets takes place in two stages; reaction between $\mathrm{FeO}$ and $\mathrm{C}$ inside the pellet, followed by reaction of the remaining carbon with the $\mathrm{FeO}$ inside the slag. A transitional stage that is sometimes too short to be measured separates these two steps.

2.Depending on the carbon and $\mathrm{FeO}$ level of DRI, the duration of each reaction stage varies. In extreme cases when carbon level is low the second stage is essentially eliminated.

3.Carbon content of DRI has a significant effect on its decarburization rate. Increasing carbon increases the reaction rate for both stages. However, this effect is more pronounced in the second stage.

4.Increasing the slag temperature promotes the rate of reaction in both stages. It also increases the degree of dependence of the second stage rate to the carbon.

5.Preheating of DRI pellets increases the rate of decarburization for the first stage while it has no significant effect on the second stage. Also, an increase in the preheating temperature from 70 to $600^{\circ} \mathrm{C}$ leads to a reduction of $23 \%$ in the overall decarburization time. 
Page 8 of 14

\section{Tables}

Table 1 - Target composition of slag (wt pet)

\begin{tabular}{ccccc}
\hline $\mathbf{F e O}$ & $\mathrm{CaO}$ & $\mathrm{SiO}_{\mathbf{2}}$ & $\mathrm{Al}_{\mathbf{2}} \mathrm{O}_{\mathbf{3}}$ & $\mathrm{MgO}$ \\
\hline 22 & 42 & 22 & 4 & 10 \\
\hline
\end{tabular}

Table 2 - Average composition of DRI pellets (wt pct)

\begin{tabular}{cccccccc}
\hline Total Fe & Metallization & $\mathrm{C}$ & $\mathrm{S}$ & $\mathrm{SiO}_{2}$ & $\mathrm{Al}_{2} \mathrm{O}_{3}$ & $\mathrm{CaO}$ & $\mathrm{MgO}$ \\
\hline 92 & 95 & 2.2 & 0.006 & 2.15 & 0.5 & 0.6 & 0.5 \\
\hline
\end{tabular}

Table 3 - Average reaction times for four preheating temperatures

\begin{tabular}{ccc}
\hline Temperature $\left({ }^{\circ} \mathbf{C}\right)$ & Average reaction time (s) & Standard deviation \\
\hline 70 & 62.0 & 17.2 \\
200 & 60.5 & 13.6 \\
400 & 56.1 & 15.5 \\
600 & 47.3 & 18.2 \\
\hline
\end{tabular}


Figures

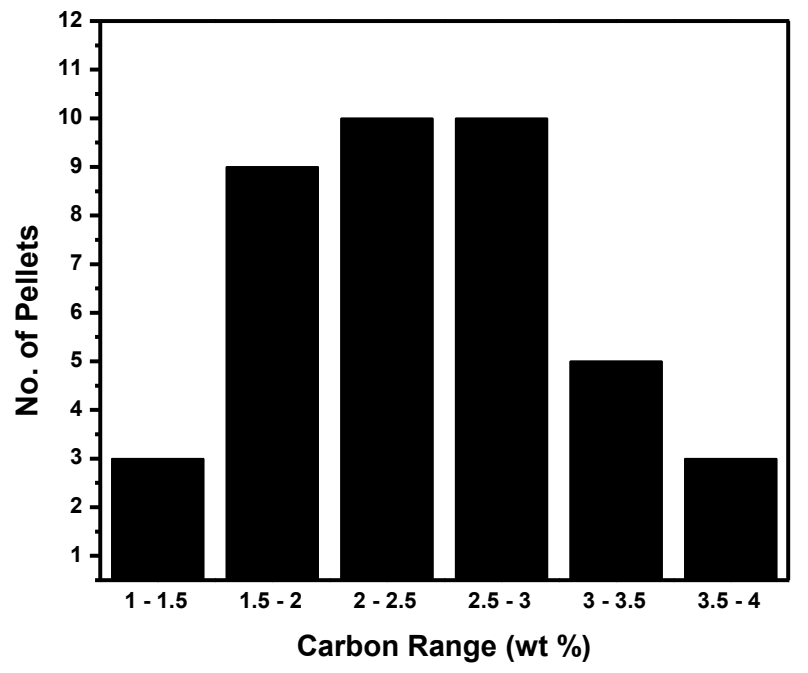

Figure 1 - Carbon distribution in the samples

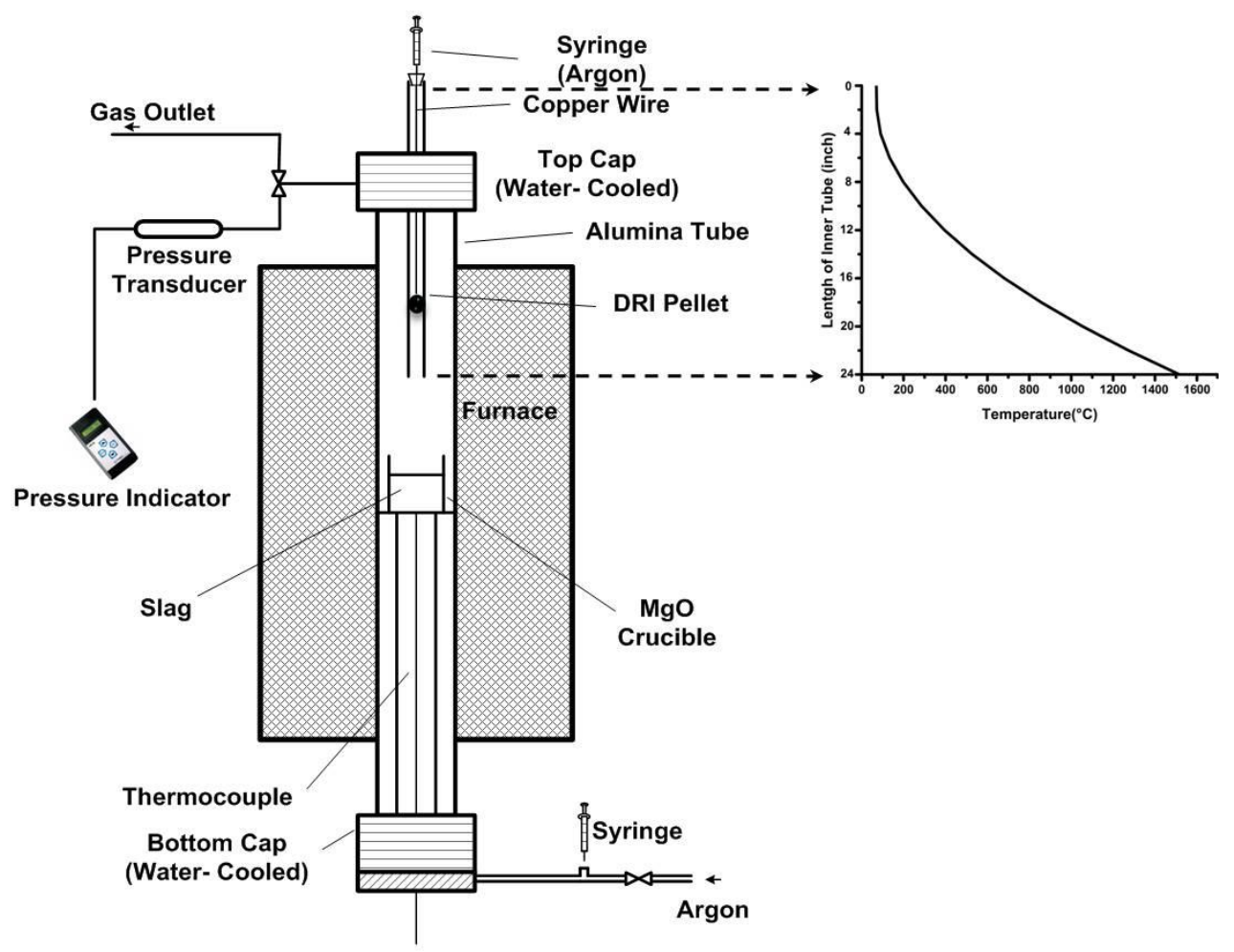

Figure 2 - Experimental arrangement for DRI preheating and kinetics measurements 


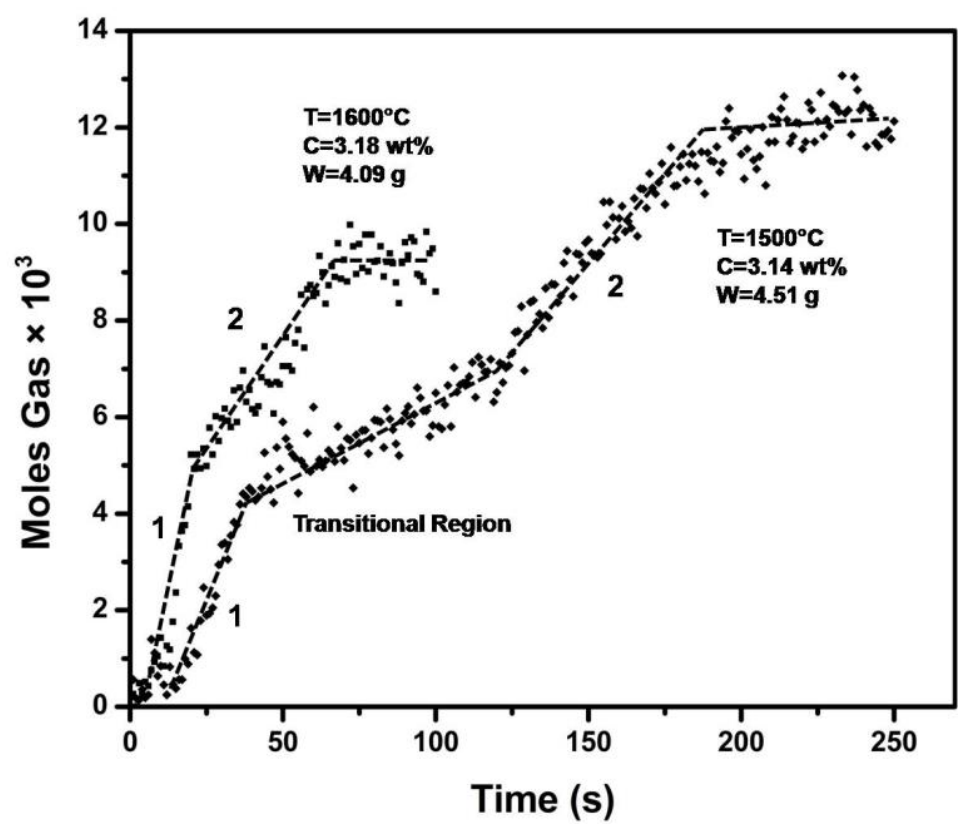

Figure 3 - Gas $v$ s. time curve for two DRI pellets at $\mathrm{T}=1600^{\circ} \mathrm{C}$ and $\mathrm{T}=1500^{\circ} \mathrm{C}$

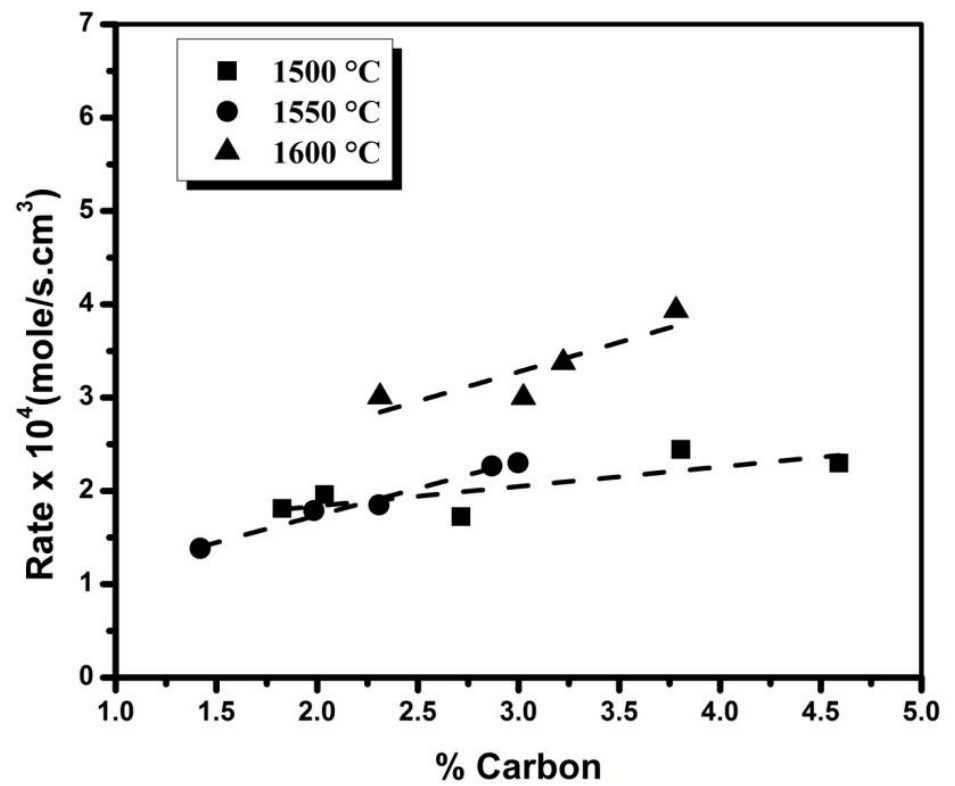

Figure 4 - Rate of reaction $v s$. carbon content in the first stage for various slag temperatures 


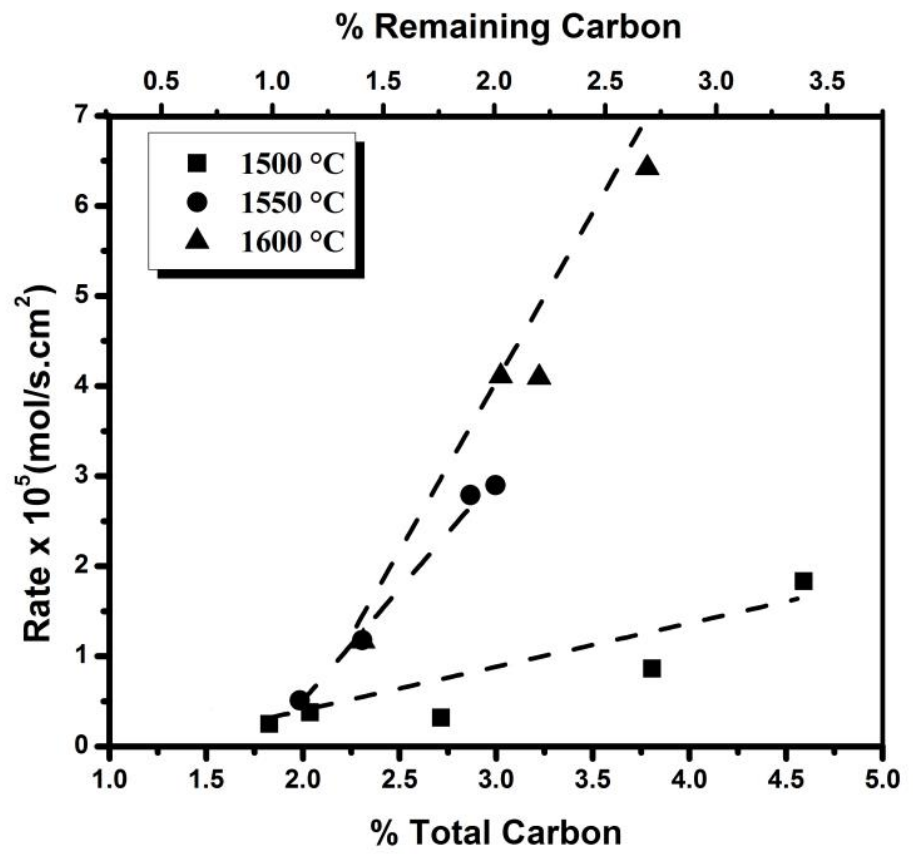

Figure 5 - Rate of reaction $v s$. carbon content in the second stage for various slag temperatures

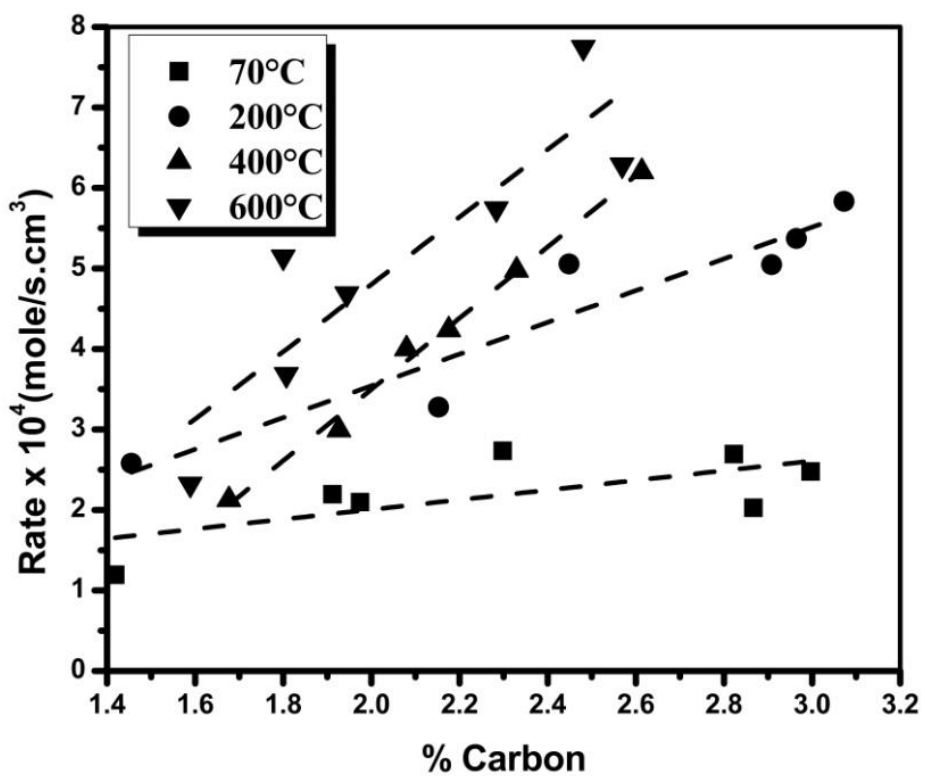

Figure 6 - Rate of gas evolution $v s . \mathrm{C}$ wt pet for four preheating temperatures (slag temperature $=1550^{\circ} \mathrm{C}$ ) 
Page 12 of 14

\section{\% Remaining Carbon}

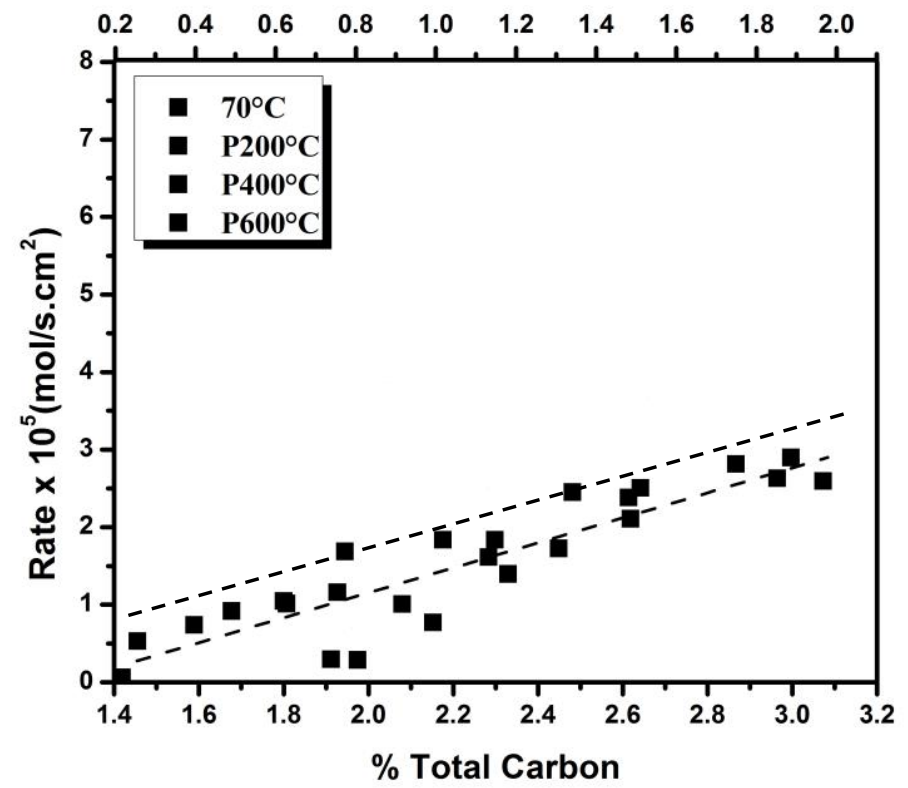

Figure 7 - Rate of gas evolution $v s$. wt pct $\mathrm{C}$ in the second stage for four preheating temperatures (slag temperature $=1550^{\circ} \mathrm{C}$ ) 


\section{References}

[1] J. Kopfle and R. Hunter: Ironmaking and Steelmaking, 2008, vol. 35, 254.

[2] M. Abel and M. Hein: AISTech 2009 Proceedings, 2009, vol. 1, 675.

[3] M. Barati, J. Li, F. Wheeler, G. Yakov, F. Atkinson, and S. Broek: VIII International Conference on Molten Slags, Fluxes and Salts 2009, vol.1, 94.

[4] F. Wheeler, S. Broek, and G. Traquair: Steel Times International, 2008, vol. 32, 19.

[5] G. Traquair, F. M. Wheeler, and Y. M. Gordon: 2007, AISTech 2007 Proceedings, 2007, vol. 1, 529.

[6] J. Li and M. Barati: Metallurgical and Materials Transactions B.vol.40, 2009, vol. 40, 17.

[7] K. Sadrnezhad and J. F. Elliott: Iron Steel Int, 1980, vol. 53, 337.

[8] D. A. Goldstein, R. J. Fruehan, and B. Ozturk: Iron and Steelmaker (USA), 1999, vol. $26,49$.

[9] D. Anghelina, G. Brooks, and G. A. Irons: Can. Metall. Q., 2007, vol. 46, 373.

[10] L. Giguere: Direct from Midrex, 2000.

[11] A. Bandopadhyay, A. Ganguly, K. N. Gupta, and H. S. Ray: Thermochimica Acta, vol. 276, 1996.

[12] E. W. Mulholland, G. S. F. Hazeldean, and M. W. Davies: Journal of the Iron and Steel Institute (London), 1973, vol. 211, 632.

[13] T. Gare and G. S. F. Hazeldean: Ironmaking and Steelmaking, 1981, vol. 8, 169.

[14] D. J. Min and R. J. Fruehan: Metallurgical Transactions B, 1992, vol. 23B, 29.

[15] R. Bailey: Direct from Midrex, 2001, vol. 1, 7.

[16] R. Viramontes-Brown, C. Lizcano-Zulaica, D. L. Pena, and M. Herrera-Garcia: AISTech 2004 Proceedings, 2004, vol. 1, 535.

[17] M. Abel and M. Hein: AISTech 2009 Proceedings, 2009, vol. 1, 675.

[18] C. L. Molloseau and R. J. Fruehan: Metallurgical and Materials Transactions B, 2002, vol. 33B, 335.

[19] E. Chen and K. Coley: VIII International Conference on Molten Slags, Fluxes and Salts MOLTEN 2009 Proceedings, 2009, vol. 1, 803.

[20] G. G. K. Murthy, Y. Sawada, and J. F. Elliott: Ironmaking and Steelmaking, 1993, vol. 20, 179. 
Figure 1 - Carbon distribution in the samples

Figure 2 - Experimental arrangement for DRI preheating and kinetics measurements

Figure 3 - Gas vs. time curve for two DRI pellets at $\mathrm{T}=1600^{\circ} \mathrm{C}$ and $\mathrm{T}=1550^{\circ} \mathrm{C}$

Figure 4 - Rate of reaction vs. carbon content in the first stage for various slag temperatures

Figure 5 - Rate of reaction vs. carbon content in the second stage for various slag temperatures

Figure 6 - Rate of gas evolution vs. wt pct $\mathrm{C}$ in the first stage for four preheating temperatures (slag temperature $=1550^{\circ} \mathrm{C}$ )

Figure 7 - Rate of gas evolution vs. wt pct $C$ in the second stage for four preheating temperatures (slag temperature $=1550^{\circ} \mathrm{C}$ ) 